\title{
Los títulos universitarios expedidos por las universidades particulares o privadas: ¿documento público o privado?
}

Alicia Angélica Asencios Agama*

- Abogado, docente universitario, Juez Penal Supernumerario, con estudios de Maestría y Doctorado. 


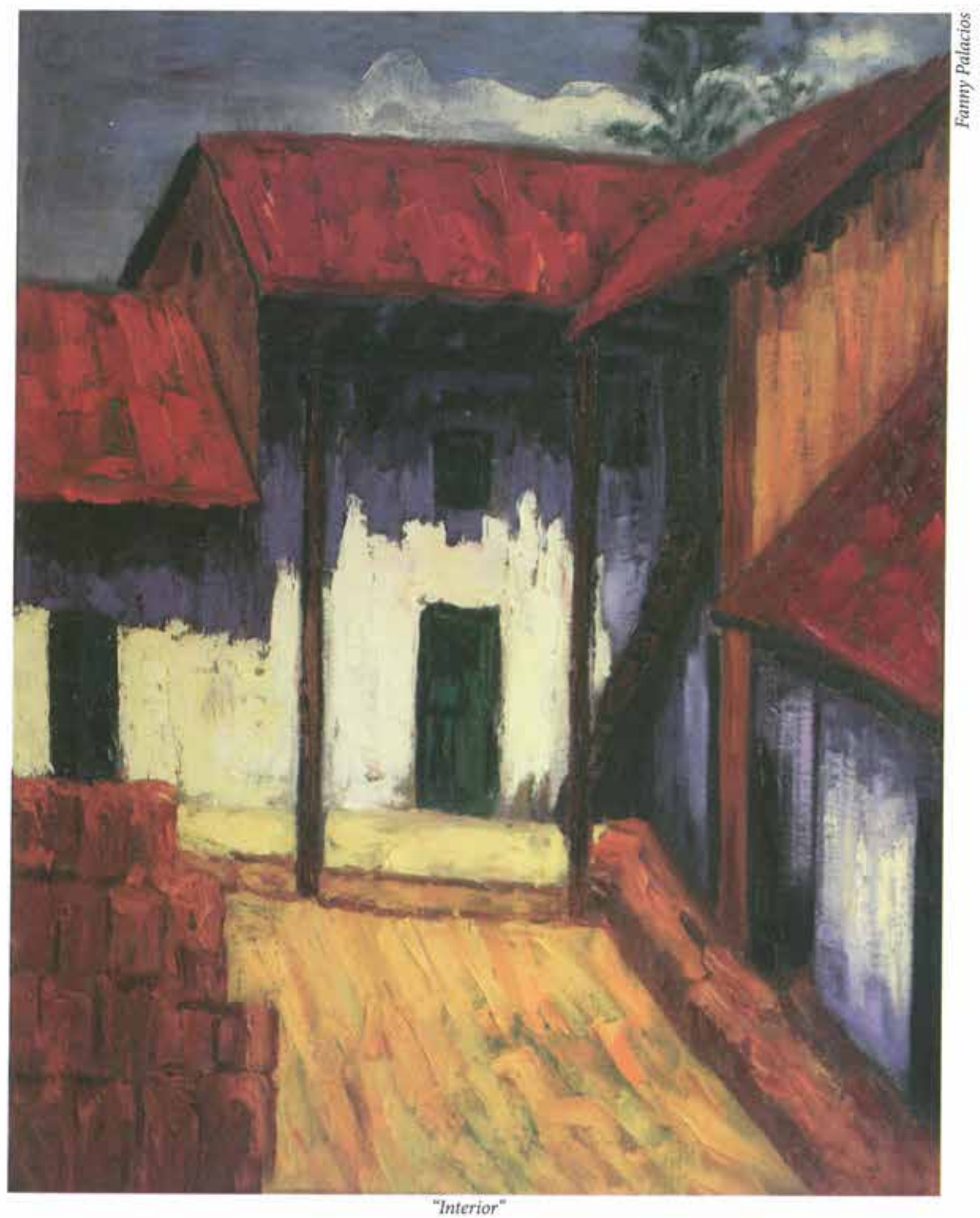


— $\mathrm{n}$ los procesos contra la fe pública y falsificación de documentos, en el que el inculpado ha falsificado o usado un título universitario falso que tenga como ente emisor a una universidad nacional al momento de su calificación, tanto el representante del Ministerio Público como el juez indican que dicho documento es de naturaleza pública. Hasta ese momento todo parece claro, pero, ¿qué ocurre cuando el título es emitido por una universidad privada o particular? Es ahí donde la uniformidad de criterios se quiebra, pues un grupo indica que su naturaleza es propia de los documentos públicos, otro grupo sostiene que se trata de documentos privados, entonces: ¡a qué se debe esa diferencia? ¿Se debe quizás al origen de la universidad?

Aquellos que sostienen que los títulos universitarios, así como los títulos de los grados académicos emitidos por una universidad particular o privada, son de naturaleza privada, basan su razonamiento en que el artículo 427 del Código Penal no lo indica. Por tanto, supletoriamente, se remiten al artículo 235 del Código Procesal Civil, puesto que, según su razonamiento, al realizar una interpretación literal de la norma, un documento es público cuando es otorgado por un funcionario público en ejercicio de sus atribuciones o por la escritura pública y demás documentos otorgados ante o por notario público, según la ley de la materia. Por tanto, todo aquel documento que no reúne dichas características es un documento privado.

Según esta interpretación, todo título a nombre de la nación, otorgado por una universidad privada o particular, es un documento privado, pero nos hacemos las siguientes preguntas: ¿acaso los títulos universitarios o los grados académicos no son emitidos exclusivamente por las universidades? Si esto es así, entonces ¿por qué existe esa diferencia? ¿Acaso tienen distinto valor? Ante estas interrogantes y con la finalidad de unificar criterios, al momento de calificar la naturaleza de los títulos universitarios emitidos por las universidades privadas y particulares, ya sea por los fiscales y jueces, es que elegimos, siguiendo a Werner Goldschmidt, los maestros Mario Alzamora Valdez y Carrión Lugo, realizar una interpretación extensiva de la norma aplicando el método sistemático. 
En efecto, este método introduce la idea de que una norma no es un mandato aislado, sino que responde al sistema jurídico normativo orientado hacia un determinado rumbo en el que, conjuntamente con otras normas, se encuentra vigente. Por esta razón, la interpretación a realizarse forma parte de un sistema y no pudiendo, a su vez, excluirse del mismo, el significado y sentido de la norma jurídica podrá ser obtenido de los principios que inspiran ese sistema. Estos principios y su respectivo significado incluso pueden ser advertidos con nitidez en el contenido de otras normas del sistema, por tanto podemos afirmar que existe conexión entre todas las normas del ordenamiento jurídico cuya base es la Constitución.

Haciendo una reseña debemos indicar, primeramente, qué se entiende por autonomía universitaria. Cabe recordar que en la Conferencia Regional, organizada por la Unesco y el Ministerio de Educación de Cuba desarrollada en La Habana en el año de 1996, se acordó que:

Las universidades deben mantener su carácter de instituciones autónomas que, de modo crítico, producen y transmiten cultura a través de la enseñanza, la investigación y la extensión, con el fin de atender las necesidades educativas del mundo contemporáneo. Esto requiere que las universidades mantengan una clara independencia política, ética y científica; y que conserven el control de su presupuesto, pudiendo orientar sus gastos hacia el cumplimiento de su misión. ${ }^{1}$

Por ende, autonomía se entiende como el poder poseído por un sistema o subsistema para llevar a cabo sus propias actividades. Por otro lado, encontramos en nuestra legislación que tanto la creación como la supresión de las universidades se realiza por ley, siendo el ente encargado de evaluar a todas las universidades, dentro del plazo previsto en la norma, la Asamblea Nacional de Rectores.

De la misma forma, el fundamento jurídico previsto en el último párrafo del artículo 18 de la Constitución Política del Perú establece que las universidades son autónomas en su régimen de gobierno académico, administrativo y económico, y que deben regirse por sus propios estatutos. Dicha autonomía le otorga derechos como el de organizar su sistema académico, económico y administrativo, conforme el inciso "b" del artículo $4^{\circ}$ de la ley 23736.

Así lo sostiene además el Tribunal Constitucional en su fundamento sexto de la sentencia número 1485-2001-AA/TC, indicando que "El sistema universitario es uno sólo en el pais, cuya 
coordinación de las universidades tanto particulares como nacionales está prevista en el artículo noventa de la Ley 23733", ${ }^{2}$ por tanto, la violación de la autonomía antes referida de la que gozan las universidades, implica una sanción por ley.

Tenemos también que el numeral seis del artículo primero del Título Preliminar de la Ley 27444 - Ley del Procedimiento Administrativo General otorga a los organismos a los que la Constitución Política del Perú y las leyes les confieren autonomía, entre las que están las Universidades, la facultad administrativa. Además, a mayor abundamiento, la Ley Universitaria - Ley 23733 confiere sólo a las universidades la facultad de otorgar a través del Consejo Universitario (párrafo "f" del artículo 32 de la Ley Universitaria), no sólo los grados académicos de Bachiller, Maestro y Doctor sino también, a nombre de la Nación, el título profesional de Licenciado.

El Estado, a través del último párrafo del artículo 18 de la Constitución Política y de los artículos 4, 22 y 31, párrafo "f" del artículo 32 de la Ley Universitaria - Ley 23733, numeral seis del artículo primero del Título Preliminar de la Ley 27444, otorga a las universidades sin distinción alguna, para que a través del Consejo Universitario, se confieran los títulos profesionales aprobados por las Facultades.

Además, faculta a las autoridades que conforman el Consejo Universitario la capacidad de rubricar y dar fe a nombre del mismo Estado. Es más, resulta de obligatorio cumplimiento que las universidades remitan cada semestre académico las copias de las actas de los títulos expedidos en dicho periodo al Registro Nacional de Grados y Títulos, conforme a lo dispuesto en el artículo segundo de la ley 25064. Más aún, para revalidar la calidad de documento público, cabe mencionar, por ejemplo, que el Consejo Ejecutivo del Poder Judicial, mediante la Resolución Administrativa número $182-2000-\mathrm{CE}$ - PJ, dispone que previamente, como requisito obligatorio, a la inscripción del Título Profesional a nombre de la Nación de abogado, se presente la certificación en las Cortes Superiores de Justicia del país, de suerte que el título profesional se encuentre inscrito en la Asamblea Nacional de Rectores.

Tenemos así que los títulos y grados académicos universitarios que acreditan la legitimidad de cualquier individuo de haber aprobado satisfactoriamente la modalidad exigida a fin de ser considerado por la sociedad como un profesional en su materia, sea que provengan de una universidad nacional, particular o privada de este país, son documentos públicos, por cuanto la autonomía universitaria proviene de la Constitución Política del Estado que faculta a las casas superiores de estudios, sin distinción, su autorregulación administrativa.

2 Tribunal Constitucional, exp. $n^{\circ}$ 1485-2001-AA/TC, sexto fundamento. 
Además, la Ley del Procedimiento Administrativo General - Ley 27444, en su artículo primero numeral seis, sostiene que los organismos a los que la Constitución Política del Perú y las leyes les confieren autonomía pertenecen a la administración pública, por ende las universidades, sean nacionales, particulares o privadas, al gozar de autonomía conforme a lo establecido en la Carta Magna, son consideradas como entidades de la administración pública, siendo legítimos, al ser de naturaleza pública, los documentos que se expiden.

Por otro lado, la doctrina nacional sostiene "el sentido que tiene el carácter público, no solo los otorgados o autorizados por funcionarios público, sino que también por quienes tienen la facultad de depositario de la fe pública en el ejercicio de su cargo"s. También puntualiza Ledesma Narváez que "constituye documento público los otorgados según la ley de la materia", ${ }^{4}$ esto último, por supuesto, se refiere a la Ley Universitaria ${ }^{\circ} 23733$.

Por último, la jurisprudencia internacional también se ha pronunciado con respecto a esta controversia. Por ejemplo, tenemos la sentencia emitida por el Juzgado Federal de primera Instancia $n^{\circ} 3$ de Argentina que indica en sus considerandos que el fallo concluye, entre otros motivos, por el carácter de funcionarios públicos que tienen los profesores y secretarios de las universidades nacionales, y si esa fuera una nota esencial para establecer el carácter de instrumento público de los títulos y certificados expedidos por las universidades privadas, la conclusión sería adversa al carácter público de los documentos emanados de ésta, valor erga homnes, requisito de autenticidad establecido legalmente y que el instrumento pudo emanar no sólo de un funcionario público sino de otras personas autorizadas por el Estado, todas esas cualidades concurren en el caso de los títulos y certificados de estudios de las universidades privadas, conforme lo establece el artículo 24 de la Ley 24521 y del art. 21 del decreto reglamentario 576/96.2, en consecuencia se concluye que los instrumentos indicados tienen carácter público.

Por tanto, luego de haber realizado el precitado análisis, cuando se presente un caso de delitos contra la Fe Pública - Falsificación de Documentos, donde el documento falsificado sea un título universitario o grado académico, no deberá dudarse al momento de su calificación de su real naturaleza, es decir, de su naturaleza de documento público.

HINOSTROZA MINGUES, Alberto. La Prueba en el Proceso Civil. Lima 1999., pág. 200.

LEDESMA NARVÁEZ, Marianella. Comentario al Código Procesal Civil. Tomo I, pág. 848. 